\title{
Morphological Changes in Diabetic Foot
}

\author{
Gurmeet Singh Sarla* \\ Senior Registrar, 159 General Hospital, India
}

Submission: November 18, 2019; Published: December 02, 2019

*Corresponding author: Gurmeet Singh Sarla, Senior Registrar, 159 General Hospital, India

\section{Abstract}

Objective: Diabetic feet and toe deformities is commonly associated with diabetes mellitus and neuropathy is the causative factor combined with vasculopathy. In this study we list out various morphological changes which occur in Diabetic foot lesions, the pathophysiology and the management of the deformed toes and feet.

Materials and Methods: A prospective study was carried out in patients presenting to the Diabetic Clinic at a tertiary care hospital in Delhi. 70 patients who were labelled as diabetics formed the study group.

Results: The most common age group affected belonged to 51-60 age bracket which included 41 patients (58.5\%). The male to female ratio was approximately 3:1. Majority of patients $32(45.71 \%)$ had diabetes of $>10$ years duration. Foot and toe deformities affected majorly diabetics with moderately controlled diabetes mellitus and the study revealed that 40 patients $(57.2 \%)$ had moderately controlled diabetes with blood sugar levels ranging from 160-200 mg/dl. The highest number of patients i.e. 29 patients (41.4\%) who had foot/ toe deformities were on oral hypoglycaemic agents. Clawing of the toes (26 patients, $37.14 \%$ of patients), was the commonest morphological change in the architecture of the foot followed by Varus deformities (17 patients, $24.28 \%$ of patients). Nail changes in the form of hypertrophied and brittle nails affected 37 patients (52.85\%).

Conclusion: We concluded that team approach, adequate diabetic control combined with patient education about foot care and footwear will help prevent complications and improved quality of life of the patients suffering from diabetic foot and toe deformities.

Keywords: Diabetic foot; Toe deformities; Hammer toes; Hallux valgus; Bunion; Claw toes; Charcot's foot

\section{Introduction}

Foot problems are common in patients with diabetes, often requiring prolonged and costly hospital stay and eventually leading to lower extremity amputation [1]. Motor neuropathy affects the function of the intrinsic and extrinsic musculature of the foot, thus upsetting the delicate balance between flexors and extensors of the toes [2]. Atrophy of the small muscles responsible for metatarsophalangeal plantar flexion is thought to lead to the development of hammertoes, claw toes and prominent metatarsal heads [3]. The prevalence of all diabetic foot complications increased clearly with age and diabetes duration [4]. Clinical recommendations for people with diabetes include provision of special footwear to individuals with foot risk factors [5].

\section{Aim}

To study the morphological changes in the form of foot and toe deformities occurring in diabetic patients presenting to a tertiary care centre in New Delhi, India.

\section{Materials and Methods}

A prospective study was carried out in patients presenting to the Diabetic Clinic at a tertiary care hospital in Delhi. The patient profile comprised of patients who were known Diabetics or recently detected diabetics under treatment and follow up and had obvious foot and/or toe deformities. A detailed history regarding foot and toe deformities was followed by a thorough physical examination and the following were noted: -

1) Age and sex of the patient

2) Duration and severity of Diabetes.

3) Treatment by Oral Hypoglycaemic agents and / or Insulin

4) Evidence of Neuropathy -loss of touch, vibration, temperature sensation, using a $10 \mathrm{gm}$ monofilament, 128 $\mathrm{Hz}$ tuning fork, deep tendon reflexes were examined using percussion hammer. 
5) Evidence of ischaemia - thinning of skin, loss of subcutaneous fat, hair loss, brittle hypertrophied nails, callous formation, ulceration, peripheral pulses and venous filling time were noted.

6) Foot and/or toe deformities

7) Nail changes

\section{Results}

Table 1: Age.

\begin{tabular}{|c|c|c|}
\hline Age group & Number of patients & Percentage \\
\hline$<40$ & 2 & 2.8 \\
\hline $41-50$ & 9 & 12.8 \\
\hline $51-60$ & 41 & 58.5 \\
\hline $61-70$ & 16 & 22.8 \\
\hline$>70$ & 2 & 2.8 \\
\hline
\end{tabular}

Table 2: Sex.

\begin{tabular}{|c|c|c|}
\hline Sex & Number of patients & Percentage \\
\hline Male & 51 & 72.86 \\
\hline Female & 19 & 27.14 \\
\hline
\end{tabular}

Table 3: Duration of diabetes.

\begin{tabular}{|c|c|c|}
\hline Duration of diabetes & Number of cases & Percentage \\
\hline Recently detected & 16 & $22.86 \%$ \\
\hline < 1year Duration & 4 & $5.71 \%$ \\
\hline 1-10 years & 18 & $25.71 \%$ \\
\hline > 10 years Duration & 32 & $45.71 \%$ \\
\hline
\end{tabular}

Out of the 70 patients, $2.8 \%$ were below 40 years of age, 9 patients (12.8\%) were in the group between 41-50. 41 patients (58.5\%) belonged to the 51-60 age group, 16 patients (22.8\%) were in the 61-70 age group and only 2 patients were in the age group above 70 years (Table 1). Out of 70 patients, 51 patients $(72.86 \%)$ were males and 19 patients $(27.14 \%)$ were females who presented with various foot and toe deformities (Table 2). Of the 70 patient, 16 patients $(22.86 \%)$ were detected to have diabetes during their first presentation to the hospital. 4 patients $(5.71 \%)$ had foot lesion with diabetes of less than 1year duration, while 18 patients $(25.71 \%)$ had diabetes of $<10$ years duration (Table 2). Majority of patients 32 (45.71\%) had diabetes of $>10$ years duration (Table 3 ). Only seven patients (10\%) had well controlled blood sugar levels, 40 patients (57.2\%) had moderately controlled diabetes with blood sugar levels ranging from $160-200 \mathrm{mg} / \mathrm{dl} .23$ patients $(32.8 \%)$ had poorly controlled diabetes (Table 4). 16 patients (22.8\%) were unaware about their disease hence were taking no treatment (Table 3). 29 patients (41.4\%) were only on oral hypoglycaemic agents, 14 patients $(20 \%)$ were being managed with insulin, 11 patients (15.7\%) were being treated with both oral hypoglycaemic agent and insulin (Table 5). Clawing of the toes (26 patients, $37.14 \%$ of patients), was the commonest morphological change in the architecture of the foot followed by Varus deformities (17 patients, $24.28 \%$ of patients) . Hallux valgus (17.14\%), Hammer toes $(14.28 \%)$, high plantar arch (5.71\%) and Charcot's foot was seen only in two $(1.42 \%)$ patients (Table 6).

Table 4: Severity of diabetes.

\begin{tabular}{|c|c|c|c|c|}
\hline & $\begin{array}{r}\text { Fastir } \\
\text { Suga }\end{array}$ & $\begin{array}{l}\text { ood } \\
/ \text { dl }\end{array}$ & No. of Patients & Percentage \\
\hline \multirow[t]{2}{*}{ MILD } & 120 & 140 & 2 & $2.80 \%$ \\
\hline & 140 & 160 & 5 & $7.10 \%$ \\
\hline \multirow[t]{2}{*}{ MODERATE } & 160 & 180 & 16 & $22.80 \%$ \\
\hline & 180 & 200 & 24 & $34.20 \%$ \\
\hline \multirow[t]{2}{*}{ SEVERE } & 200 & 220 & 14 & $20.00 \%$ \\
\hline & $>$ & 220 & 9 & $12.80 \%$ \\
\hline
\end{tabular}

Table 5: Treatment agents used for diabetes on presentation with foot and toe deformities.

\begin{tabular}{|c|c|c|}
\hline Treatment & Number of Patients & Percentage \\
\hline No treatment & 16 & $22.80 \%$ \\
\hline $\begin{array}{c}\text { Oral Hyponymic agents } \\
\text { (OHA) }\end{array}$ & 29 & $41.40 \%$ \\
\hline Insulin & 14 & $20.00 \%$ \\
\hline OHA + Insulin & 11 & $15.70 \%$ \\
\hline
\end{tabular}

Table 6: Foot/ Toe deformities.

\begin{tabular}{|c|c|c|}
\hline Characteristic & No. of Patients & Percentage \\
\hline Claw Toes & 26 & $37.14 \%$ \\
\hline Varus deformity & 17 & $24.28 \%$ \\
\hline Hallux Valgus & 12 & $17.14 \%$ \\
\hline Hammer Toes & 10 & $14.28 \%$ \\
\hline High Plantar Arch & 4 & $5.71 \%$ \\
\hline Charcot's Foot & 1 & $1.42 \%$ \\
\hline
\end{tabular}

\section{Nail Changes}

Hypertrophy with brittle nails (52.85\%) were seen in 37 patients.

\section{Follow Up}

All patients were followed up at monthly intervals whenever they used to come to collect their medicines for diabetes. They were given specific advice about foot care and footwear.

\section{Discussion}

\section{Normal foot}

The skin of the healthy foot is elastic but resilient. It should not show signs of scaliness, dryness or brittleness, nor should it be thin and shiny. Plantar skin is about twice as thick as that on the dorsum, is tougher and moves less readily over the deeper structures. 


\section{Gait cycle}

During walking the weight is taken first on the point of the heel ("heel strike"). It is then transferred smoothly to the outer aspect of the sole and the metatarsal heads of the second to fifth toes. It then shifts medially to the foot (first metatarsal head) and the body is propelled forward by flexion of all the metatarsals, and of the big toe ("toe off"). This smooth transfer of forces is lost when the foot loses its normal plantar arch, or the ligaments and soft tissues become less elastic. The result is that some parts of the sole take increased pressure and therefore become liable to neuropathic ulceration. This is most likely to occur over the second and third metatarsal heads, and the big toe.

\section{Diabetic foot}

Most significant changes in the foot occur in the presence of neuropathies. Neuropathy of distal lower extremities is subdivided into sensory, motor and autonomic peripheral neuropathy [6]. Sensory neuropathy causes loss of vibration sense, pressure and touch sensations. Motor neuropathy can be seen in the form of atrophy of small foot muscles resulting in malposition of toes (claw toe). Loss of Achilles tendon reflex is an early sign of motor neuropathy [7]. Motor neuropathy leads to an imbalance between the flexors and extensors of the toes resulting in a deformed foot, altering the biomechanics of the foot.

\section{Peripheral neuropathy}

Sensory Neuropathy: Diabetes leads to abnormal function of peripheral nerves due to Metabolic causes -due to accumulation of sorbitol. Ischaemia - the nerves dependent on the vasa nervous for their nutrient supply which suffer ischaemic damage from microvascular disease.

\section{Motor neuropathy}

The integrity of the arch of the foot is preserved by muscles, ligaments and connective tissue. The muscles become weak and atrophic when affected by motor neuropathy. This causes loss of normal balance between the toe flexors and extensors; hence the persons may develop either a flat foot or one which is excessively clawed.

\section{Autonomic neuropathy}

Vasomotor: The fine control of distribution of blood is dependent on the action of Vasomotor nerves. These are responsible for opening and closing of arterioles and venules such that blood is shunted to the areas where it is most needed. The foot affected by autonomic neuropathy may have abnormal distribution of blood even though the macrovascular supply is good. The altered blood flow due to arterio-venous shunting leads to increased bone turnover, resorption and destruction of bones and joints called the Charcot's joint. Charcot joint was considered when bones, joints, and soft tissues of the foot and ankle are inflamed in the presence of neuropathy with or without history of trauma leading to variable degrees of bone destruction, subluxation, dislocation, and deformity [8].

\section{Sweating}

Autonomic neuropathy may result in sudomotor dysfunction leading to abnormal sweating and dry skin with cracking and fissuring facilitating the bacterial infection of the foot [9]. The risk for diabetic foot ulceration increases by sevenfold in patients with peripheral diabetic neuropathy [10]. $45 \%$ to $60 \%$ of all ulcerations in patients with diabetes are mainly due to neuropathy, while $45 \%$ of the ulcers are due to combined neuropathic and ischemic factors [10]. Distal bilateral symmetrical neuropathy is the commonest presentation and usually starts in the lower limbs, has a progressive course. It usually presents in a glove and stocking pattern of abnormal sensations [11]. "Burning feet syndrome." is a form of neuropathy which arises at night and is accompanied by high sensation of pain [12]. Peripheral neuropathy is accompanied by autonomic neuropathy in $30 \%$ to $50 \%$ of cases [13]. The foot skin affected by autonomic neuropathy is dry and fissured with the consequence of finding a reduced protective skin function and thus increased risk of injury.

\section{Lesions of neuropathic foot}

a) The foot is typically pale and puffy, with clawing of toes. The skin is dry and fissured and the planter arch may be exaggerated. Clawed toes are defined as toes with extension of the metatarsophalangeal joint and flexion of the proximal and distal interphalangeal joints. Claw toes is caused by an imbalance between the extrinsic and intrinsic foot muscles [14].

b) Hammer toes: The metatarsophalangeal joint of the first digit is extended, and the proximal interphalangeal joint is flexed. Atrophy of the small muscles responsible for metatarsophalangeal plantar flexion is thought to lead to the development of hammer toes [15].

c) Varus deformities: The third, fourth and fifth toes drift medically due to muscle imbalance, to gouge adjacent toes producing ulcers.

d) Hallux Valgus: Hallux valgus is defined as a lateral angulation of the first MTP joint of the great toe [16].

e) Tailor's Bunion: It is an exostosis of the lateral part of the fifth metatarsal head which is associated with Varus deformity.

f) Charcot's foot: It is a rare but serious complication of the diabetic foot. It occurs in less than $1 \%$ of people with diabetes, most commonly during the fifth and sixth decade in insulin dependent patients.

The duration of diabetes is usually greater than 12 years. Normally it develops unilaterally, but in $20 \%$ of patients it develops bilaterally. It is defined as a chronic, painless degenerative process affecting the weight bearing joints of the foot. The ethology is thought to be repeated minor trauma in a neuropathic foot and due to arterio- venous shunting. Charcot's 
foot develops through 3 stages, described by Eichholtz in 1966. Eichholtz stage 1 is characterized by acute inflammation associated with hyperaemia and erythema. During this stage, the bone softens and fragments, fracture dislocations occur, with pure dislocations more common. Stage 2 is characterized by bony coalescence, reduction in swelling of the foot, and periosteal new bone formation. In stage 3 bony consolidation and healing occurs. Normally, this whole process lasts about 2 to 3 years, although progress through the stages can be quite rapid.

\section{Limited joint mobility}

Diabetes causes abnormalities of the connective tissue due to glycosylation of proteins like collagen which renders it stiff

\section{Nail care}

and inflexible. These changes restrict foot mobility, which while walking leads to trauma and ulceration.

\section{Management of Foot and toe deformities in Diabetes Mellitus}

Multidisciplinary foot care team consisting of diabetologist, surgeon, diabetic nurse, chiropodist and orthotist forms the foot care team

\section{Skin care}

The feet are often dry and scaly as a result of anhidrosis secondary to autonomic neuropathy. Regular applications of moisturizing creams will help soften the skin and prevent skin fissures which might get infected.

Figure 1: The nails should be cut straight across.

Obesity and poor eyesight prevent elderly patients to cut their nails properly which may lead to damage of the adjacent skin or may leave a portion of nail uncut, resulting in an ingrowing toenail (Figure 1). The toenails should be cut short with no remaining sharp edges. Mycological infections should be diagnosed early and be treated. A grossly deformed mycotic nail should be treated by nail excision.

\section{Use of proper footwear}

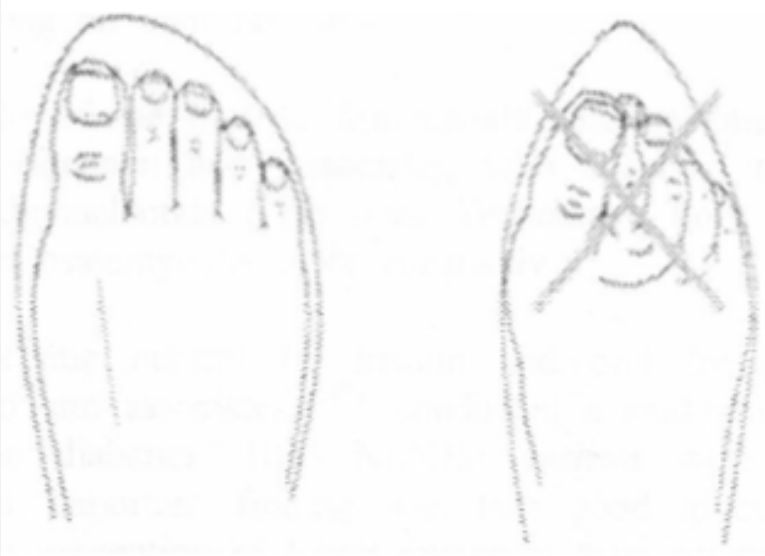

Figure 2: The internal width of the shoe should be equal to or preferably more than the width of the foot. 
Proper footwear help reduce points of high pressures. In most of the cases, the problem is caused by arching of the foot resulting in high pressure at the metatarsal heads. Custom Fitted Shoes should have generous instep support to re-distribute the weight more evenly (Figure 2). The problem of clawing is that there is an increased requirement of a deep shoe. The principle of good footwear is to provide a shoe which is deep, broad but not floppy. The material should be soft with good in step support. Bespoke footwear may be needed for feet which are grossly deformed following Charcot's arthropathy.

\section{Conclusion}

Diabetes affects the foot in various ways including lesions affecting the skin, nails, bones and connective tissues. Team approach, adequate diabetic control combined with patient education about foot care and footwear will help prevent complications and improved quality of life of the patients suffering from diabetic foot and toe deformities. Studies have confirmed that inappropriate footwear is the most common source of trauma and cause of ulceration in patients with diabetes [17] and hence patients with diabetes should be educated regarding use of proper footwear.

\section{References}

1. Ramsey SD, Newton K, Blough D, McCulloch DK, Sandhu N, et al (1999) Incidence, outcomes, and costs of foot ulcers in patients with diabetes. Diabetes Care 22(3): 382-387.

2. Grunfeld C (1992) Diabetic foot ulcers: Etiology, treatment, and prevention. Adv Intern Med 37: 103-132.

3. Caselli A, Pham H, Giurini J, Armstrong D, Veves A (2002) The forefootto-rearfoot plantar pressure ratio is increased in severe diabetic neuropathy and can predict foot ulceration. Diabetes Care 25(6): 1066-1071.

This work is licensed under Creative Commons Attribution 4.0 License

DOI: 10.19080/IJOPRS.2019.04.555637
4. Katsilambros N, Tentolouris N, Tsapogas P, Dounis E (2003) Atlas of Diabetic Foot. Chichester, UK: Wiley-Blackwell.

5. Apelqvist J, Bakker K, van Houtum WH, Nabuurs-Franssen MH, Schaper NC (2000) International consensus and practical guidelines on the management and the prevention of the diabetic foot. International Working Group on the Diabetic Foot. Diabetes Metab Res Rev S84-92.

6. Gilbey SG (2004) Neuropathy and foot problems in diabetes. Clin Med 4: 318-323.

7. Said G (2013) Diabetic neuropathy. Handbook Clin Neurol 115: 579589.

8. Rogers LC, Frykberg RG, Armstrong DG, Boulton AJM, Edmonds M, et al. (2011) The Charcot foot in diabetes. J Am Podiatr Med Assoc 101: 437-446.

9. Shaw JE, Boulton AJ (1997) The pathogenesis of diabetic foot problems: an overview. Diabetes S58-S61.

10. Reiber GE, Vileikyte L, Boyko EJ, del Aguila M, Smith DG, et al. (1999) Causal pathways for incident lower-extremity ulcers in patients with diabetes from two settings. Diabetes Care 22(1): 157-162.

11. Tesfaye S (2006) Diabetic neuropathy. In: Boulton AJM, Cavanagh PR and Rayman G The foot in diabetes, editors. Chichester, England; Hoboken, NJ: Wiley pp.30-40.

12. Tavee J, Zhou L (2009) Small fiber neuropathy: A burning problem. Cleve Clin J Med May 76(5): 297-305.

13. Ziegler D, Keller J, Maier C, Pannek J (2014) Diabetic neuropathy. Exp Clin Endocrinol Diabetes 122(7): 406-415.

14. (1988) Boulton M Clin NA pp.1513-pp.1530.

15. Caselli A, Pham H, Giurini J, Armstrong D, Veves A (2002) The forefootto-rearfoot plantar pressure ratio is increased in severe diabetic neuropathy and can predict foot ulceration. Diabetes Care 25(6): 1066-1071.

16. Joseph TN, Mroczek KJ (2007) Decision making in the treatment of hallux valgus. Bull NYU Hosp Jt Dis 65(1): 19-23.

17. Macfarlane RM, Jeffcoate WJ (1997) Factors contributing to the presentation of diabetic foot ulcers. Diabet Med 14(10): 867-870.

Your next submission with Juniper Publishers will reach you the below assets

- Quality Editorial service

- Swift Peer Review

- Reprints availability

- E-prints Service

- Manuscript Podcast for convenient understanding

- Global attainment for your research

- Manuscript accessibility in different formats

( Pdf, E-pub, Full Text, Audio)

- Unceasing customer service

Track the below URL for one-step submission

https://juniperpublishers.com/online-submission.php 